\title{
Short Communication: Rate of Propionate Infusion Within Meals Does Not Influence Feeding Behavior
}

\author{
B. J. Bradford ${ }^{1}$ and M. S. Allen ${ }^{2}$ \\ Department of Animal Science, Michigan State University, East Lansing 48824
}

\begin{abstract}
Propionate has been shown to depress the feed intake of ruminants, but whether the rate of propionate infusion influences this response is unknown. To test this possibility, the rate of propionate infused within meals was altered while the total amount of propionate infused was held constant. Eight multiparous Holstein cows ( $51 \pm 19 \mathrm{~d}$ in milk, $44.0 \pm 4.8 \mathrm{~kg} / \mathrm{d}$ of milk; mean $\pm \mathrm{SD})$ were randomly assigned to the treatment sequence in a crossover experiment with a 10-d diet adaptation period, 24-h treatment periods, and $3 \mathrm{~d}$ between treatments. Treatments were intraruminal infusion of $1.26 \mathrm{~mol}$ of $\mathrm{Na}$ propionate $(2.33 \pm 0.06 \mathrm{~L}, 0.54 \mathrm{M}, \mathrm{pH}$ 6.0) over the course of either $5 \mathrm{~min}$ (fast) or $15 \mathrm{~min}$ (slow) at each spontaneous meal. The experimental diet included high-moisture corn and was formulated for $27 \%$ neutral detergent fiber, 36\% starch, and $17.5 \%$ crude protein. Feeding behavior was monitored by a computerized data acquisition system that triggered infusion pumps at the initiation of meals, and consecutive infusions began at least 15 min apart under both treatment protocols. Feeding behavior data were analyzed to quantify the number, size, length, and time between all meals. Compared with pretreatment intake, propionate infusions depressed feed intake by 20 and $23 \%$, respectively, for the slow and fast treatments. However, the rate of propionate infusion did not significantly alter dry matter intake, meals/day, meal size, meal length, or intermeal interval. We found no evidence that the rate of infusion, within the range of typical meal lengths, determines the extent of hypophagia from propionate.
\end{abstract}

Key words: propionate, infusion rate, feeding behavior, feed intake

Propionate plays an important role as a regulator of feed intake in ruminants fed high-starch diets. Continu-

Received November 8, 2006.

Accepted January 15, 2007.

${ }^{1}$ Current address: 127 Call Hall, Kansas State University, Manhattan, KS 66506.

${ }^{2}$ Corresponding author: allenm@msu.edu ous infusion of propionate was found to depress feed intake of lactating cows in a dose-dependent manner, primarily by decreasing meal size (Oba and Allen, 2003a,c). Choi and Allen (1999) also showed that intraruminal infusion of $\mathrm{Na}$ propionate at spontaneous meals decreased feed intake relative to isomolar infusions of $\mathrm{Na}$ acetate and $\mathrm{NaCl}$. These observations, in combination with data suggesting that propionate delivery to the liver can increase significantly within the course of a meal (Benson et al., 2002), led us to hypothesize that propionate depresses feed intake by decreasing the time required to stimulate satiety within a meal (Allen et al., 2005). However, if hepatic oxidation of propionate is required for its satiating effects, then the fate of propionate within the liver will determine the extent to which feed intake is depressed. If propionate flux into the liver outpaces the capacity for gluconeogenesis, excess propionate will likely be oxidized. Therefore, the rate of propionate absorption may be as important as total propionate uptake as a limitation to feed intake. To test this hypothesis, we assessed the effects of propionate infusion rate, independent of the infusion amount, on feeding behavior and DMI of lactating dairy cows.

Eight multiparous Holstein cows ( $51 \pm 19$ DIM, 44.0 $\pm 4.8 \mathrm{~kg} / \mathrm{d}$ of milk; mean $\pm \mathrm{SD}$ ) with ruminal cannulas were selected from the Michigan State University Dairy Cattle Teaching and Research Center and were randomly assigned to treatment sequence in a crossover experiment with a 10-d diet adaptation period, 24-h treatment periods, and $3 \mathrm{~d}$ between treatments. Treatments were an intraruminal infusion of $1.26 \mathrm{~mol}$ of $\mathrm{Na}$ propionate $(2.33 \pm 0.06 \mathrm{~L}, 0.54 \mathrm{M}, \mathrm{pH} 6.0)$ over the course of either $5 \mathrm{~min}$ (fast) or $15 \mathrm{~min}$ (slow) at each meal for $24 \mathrm{~h}$. Infusion amounts were chosen based on preliminary experiments, with the goal of depressing DMI by $\sim 35 \%$; infusion rates were selected in an attempt to maximize treatment differences while constraining the slow treatment to the expected length of a typical spontaneous meal. The experimental diet (Table 1) was formulated to promote endogenous propionate production to ensure that propionate was a primary factor regulating feed intake. Throughout the ex- 
Table 1. Ingredients and nutrient composition of experimental diet ${ }^{1}$

\begin{tabular}{lc}
\hline Item & Amount \\
\hline Diet ingredient & \\
Corn silage & 31.0 \\
High-moisture corn grain & 28.4 \\
Alfalfa haylage & 14.8 \\
${\text { Modified expeller soybean } \text { meal }^{2}}^{\text {Mineral and vitamin mix }}{ }^{3}$ & 8.9 \\
Soybean meal & 8.6 \\
Nutrient composition & 8.4 \\
DM & \\
OM & 46.8 \\
Starch & 92.8 \\
NDF & 30.1 \\
CP & 27.3 \\
\hline
\end{tabular}

${ }^{1}$ Values other than DM are expressed as a percentage of dietary DM.

${ }^{2}$ SoyPlus (donation from West Central Soy, Ralston, IA).

${ }^{3}$ Mineral and vitamin mix contained $67.9 \%$ dry ground corn, $13.1 \%$ limestone, $8.5 \%$ magnesium sulfate, $6.4 \%$ salt, $2.9 \%$ dicalcium phosphate, $0.9 \%$ trace mineral premix, and $0.3 \%$ vitamin $A, D, E$ premix.

periment, cows were housed indoors in tie stalls and fed a TMR once daily $(1130 \mathrm{~h})$ at $110 \%$ of expected intake. Cows were not allowed access to feed between $1000 \mathrm{~h}$ and $1130 \mathrm{~h}$ each day while orts and the amount of feed offered were weighed for each cow. Diet ingredients and orts samples were dried in a $55^{\circ} \mathrm{C}$ forced-air oven for $72 \mathrm{~h}$ and analyzed for DM concentration. Ingredient samples were ground with a Wiley mill (1-mm screen; Authur H. Thomas, Philadelphia, PA) and analyzed for ash, NDF, CP, and starch content as previously described (Bradford and Allen, 2004). At the end of each infusion period, ruminal contents were sampled from 5 sites throughout the rumen and squeezed through a nylon screen (1-mm pore size) to collect the liquid phase. Ruminal fluid $\mathrm{pH}$ was measured using a portable $\mathrm{pH}$ meter (model 230A, ATI Orion, Boston, MA), and samples were frozen at $-20^{\circ} \mathrm{C}$ until analysis. Concentrations of VFA in ruminal fluid were determined as previously described (Oba and Allen, 2003b).

On treatment days, feeding behavior was monitored by a computerized data acquisition system (Dado and

Table 2. Effects of propionate infusion rate on feeding behavior of lactating cows ${ }^{1}$

\begin{tabular}{lcclc}
\hline Item & Fast $^{2}$ & Slow $^{2}$ & SEM & $P$ \\
\hline DMI (kg/d) & 18.6 & 19.1 & 1.3 & 0.61 \\
Meal size (kg of DM) & 1.48 & 1.49 & 0.17 & 0.93 \\
Meals/d & 12.9 & 12.8 & 0.7 & 0.87 \\
Meal length (min) & 22.6 & 24.3 & 1.1 & 0.20 \\
Intermeal interval (min) & 82.8 & 82.6 & 5.7 & 0.98
\end{tabular}

\footnotetext{
${ }^{1}$ Values are means, $\mathrm{n}=8$.

${ }^{2}$ Fast: infusions of $1.26 \mathrm{~mol}$ of $\mathrm{Na}$ propionate administered over 5 min; slow: infusions of $1.26 \mathrm{~mol}$ of $\mathrm{Na}$ propionate administered over 15 min.
}

Allen, 1993) that triggered peristaltic infusion pumps at the initiation of each new meal. Weight of the feed manger was monitored every $5 \mathrm{~s}$, and when the running standard deviation reached a threshold, an "eating flag" was triggered on the computer. Because of differences in behavior, the SD threshold was set for each cow individually based on $3 \mathrm{~d}$ of observation prior to the initial treatment (range $=1.25$ to 2.75 ). Infusions were initiated only when the eating flag was triggered 5 times within $100 \mathrm{~s}$. Midmeal infusions were prevented by requiring that the eating flag was triggered less than 13 times in the preceding $5 \mathrm{~min}$. Consecutive infusions began at least 15 min apart under both treatment protocols to prevent potential treatment bias. Feeding behavior data were analyzed to quantify the number, size, length, and time between all meals. Statistical analyses were carried out using a mixed model with fixed effects of period, treatment, and period $\times$ treatment interaction, and the random effect of cow.

Triggering infusions based on real-time monitoring of feeding behavior resulted in reasonably good relationships between infusion events and meals, identified by post hoc analysis. There was a mean of 2.9 false positives (infusions without meals) out of a total of 15.6 infusions/cow per $\mathrm{d}$, and 0.1 false negatives (meals without infusions)/cow per d. A numerically greater volume of $\mathrm{Na}$ propionate was infused for the slow treatment compared with the fast treatment $(38.6$ vs. $34.1 \mathrm{~L} / \mathrm{d}$, $P=0.21$ ), due in part to a numerically greater number of false-positive infusions (3.63 vs. $2.25 / \mathrm{d}, P=0.19$ ).

Compared with the day prior to each treatment day, propionate infusion at meals depressed DMI by 20 and $23 \%$, respectively, for the slow and fast treatment. However, the rate of infusion had no detectable influence on DMI or on measures of feeding behavior $(P>0.10$; Table 2 ). In addition, to assess whether the numerically greater amount of propionate infused for the slow treatment biased these results, energy intake from both infusate and feed consumed was calculated by assuming $\mathrm{ME}$ values of $1.537 \mathrm{MJ} / \mathrm{mol}$ for propionate (Sheperd and Combs, 1998) and $11.4 \mathrm{MJ} / \mathrm{kg}$ of DM for the TMR (calculated from NRC, 2001). Treatment had no effect on calculated ME intake ( $P=0.43$, data not shown). The propionate infusion rate did not alter ruminal $\mathrm{pH}$ $(P=0.38$, mean $=6.38)$ or ruminal propionate concentration $(P=0.74$, mean $=46.9 \mathrm{mM})$ at the end of the infusion periods.

Data from 2 preliminary studies were included in an expanded data set to examine whether DMI responses to the infusion rate were dose dependent. Protocols from these 2 studies were identical to those described above, except that solutions of $\mathrm{Na}$ propionate were of different concentrations ( 0.27 and $1.0 \mathrm{M}$, respectively). The preliminary experiments were randomized complete block 


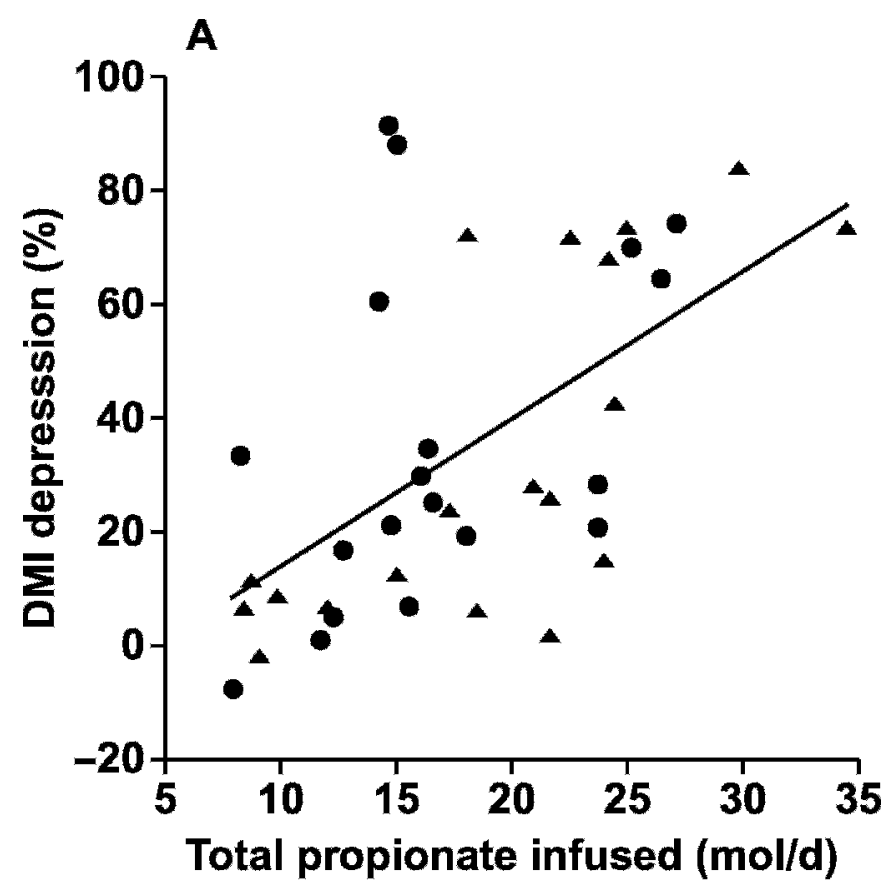

B

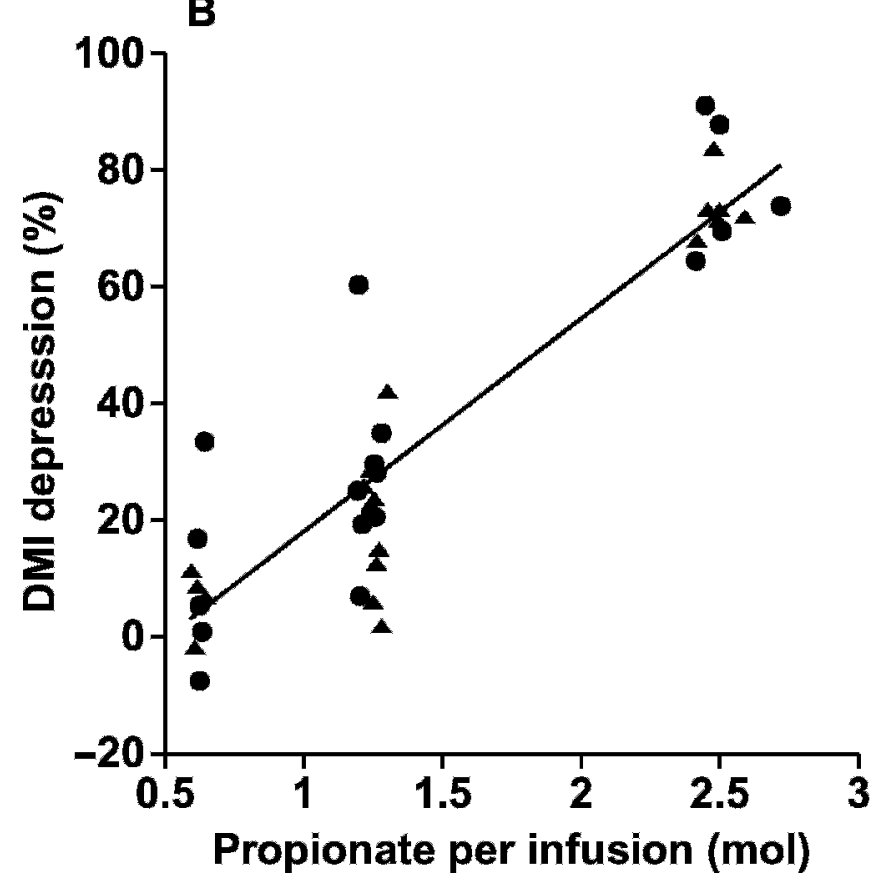

Figure 1. Propionate infusion at spontaneous meals depressed feed intake in a dose-dependent manner. Fast (৩): individual infusions administered over $5 \mathrm{~min}$; slow ( $\mathbf{\Delta})$ : individual infusions administered over $15 \mathrm{~min}$. (A) Total amount of propionate infused over 24 $\mathrm{h}$, but not infusion rate, determined the degree of DMI depression by infused propionate. $\mathrm{R}^{2}=0.33$, root mean square error $=24.5, P<$ $0.001, \mathrm{n}=38$. (B) Amount of propionate infused at each meal also predicted DMI depression. $\mathrm{R}^{2}=0.83$, root mean square error $=12.5$, $P<0.001, \mathrm{n}=38$.

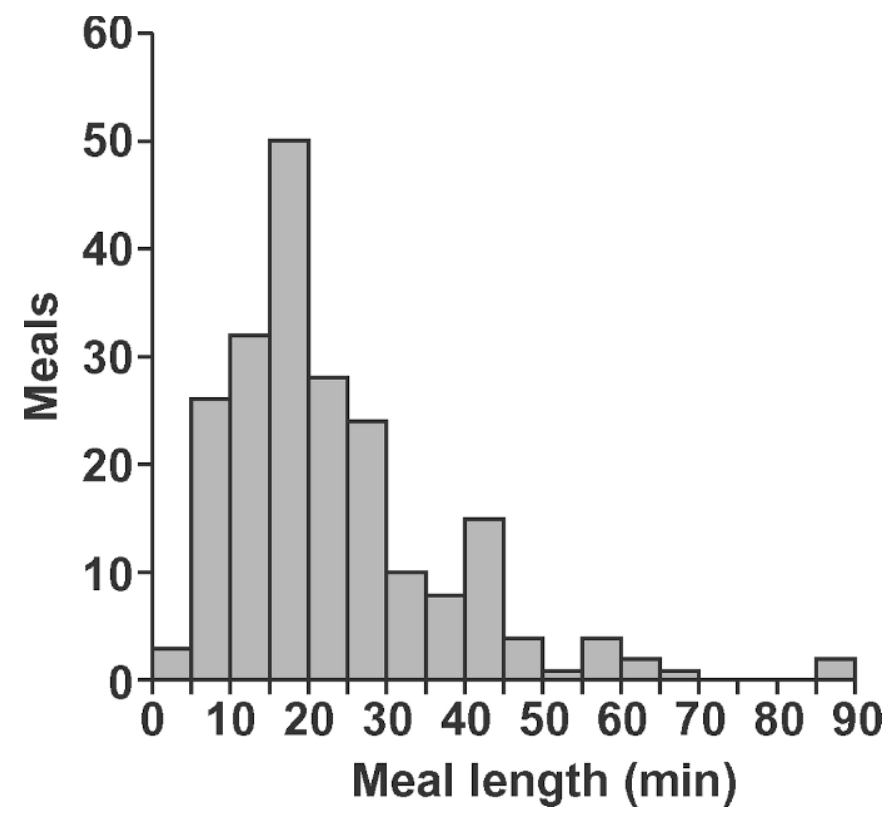

Figure 2. Distribution of meal lengths on infusion days. The histogram represents 210 meal bouts from $2 \mathrm{~d}$ ( $\mathrm{n}=8$ cows).

designs, so DMI depression was expressed as a percentage of DMI on the preceding $2 \mathrm{~d}$ to account for individual variation in baseline DMI. Intraruminal infusion of propionate at the beginning of spontaneous meals decreased DMI in a dose-dependent manner (Figure 1A), similar to what was observed previously with continuous infusion in cows (Oba and Allen, 2003c) and mealinitiated infusions in goats (Baile and Mayer, 1969). Depression of DMI was not influenced by the fast or slow treatment across experiments. However, the amount of propionate infused per meal (Figure 1B) better predicted intake responses than did the total amount of propionate infused (root mean square error: 12.5 vs. 24.5). Although these data are derived from several experiments and have confounding factors, it is nonetheless interesting that infusion of $2.5 \mathrm{~mol}$ of Na propionate at each meal depressed intake of all cows by at least $60 \%$, whereas total infusions approaching 25 $\mathrm{mol} / \mathrm{d}$ depressed intake of some cows by less than $20 \%$.

The theoretical basis for this experiment was the idea that relative utilization of propionate for oxidation, rather than glucose production, determines the feed intake response to propionate (Allen et al., 2005). Although our current results do not support this hypothesis, treatments may not have been adequately different to alter propionate flux through these pathways. Meal lengths across treatments averaged $23.1 \pm 14.2 \mathrm{~min}$ (SD), and $73 \%$ of meals were longer than 15 min (Figure 2 ), suggesting that the slow treatment could have been infused over a longer period. Furthermore, our results 
suggest that patterns of propionate production over the course of the day may influence feeding behavior independent of total production (Figure 1). Although differences in infusion rate within meals did not alter feeding behavior, the possibility remains that use of propionate for oxidation vs. gluconeogenesis influences DMI in lactating dairy cows.

\section{ACKNOWLEDGMENTS}

This material is based on work partially supported by Provimi Holding BV (Rotterdam, the Netherlands) and by a National Science Foundation Graduate Research Fellowship. The authors thank R. E. Kreft, R. A. Longuski, D. G. Main, Y. Ying, and J. A. Voelker Linton for their technical assistance and J. R. Newbold (Provimi) for useful discussions.

\section{REFERENCES}

Allen, M. S., B. J. Bradford, and K. J. Harvatine. 2005. The cow as a model to study food intake regulation. Annu. Rev. Nutr. $25: 523-547$.
Baile, C. A., and J. Mayer. 1969. Depression of feed intake of goats by metabolites injected during meals. Am. J. Physiol. 217:1830-1836.

Benson, J. A., C. K. Reynolds, P. C. Aikman, B. Lupoli, and D. E. Beever. 2002. Effects of abomasal vegetable oil infusion on splanchnic nutrient metabolism in lactating dairy cows. J. Dairy Sci. 85:1804-1814.

Bradford, B. J., and M. S. Allen. 2004. Milk fat responses to a change in diet fermentability vary by production level in dairy cattle. J. Dairy Sci. 87:3800-3807.

Choi, B. R., and M. S. Allen. 1999. Intake regulation by volatile fatty acids and physical fill. S. Afr. J. Anim. Sci. 29:40-41. (Abstr.)

Dado, R. G., and M. S. Allen. 1993. Continuous computer acquisition of feed and water intake, chewing reticular motility, and ruminal pH of cattle. J. Dairy Sci. 76:1589-1600.

NRC. 2001. Nutrient Requirements of Dairy Cattle. 7th rev. ed. Natl. Acad. Sci., Washington, DC.

Oba, M., and M. S. Allen. 2003a. Dose-response effects of intrauminal infusion of propionate on feeding behavior of lactating cows in early or midlactation. J. Dairy Sci. 86:2922-2931.

Oba, M., and M. S. Allen. 2003b. Effects of corn grain conservation method on feeding behavior and productivity of lactating dairy cows at two dietary starch concentrations. J. Dairy Sci $86: 174-183$

Oba, M., and M. S. Allen. 2003c. Intraruminal infusion of propionate alters feeding behavior and decreases energy intake of lactating dairy cows. J. Nutr. 133:1094-1099.

Sheperd, A. C., and D. K. Combs. 1998. Long-term effects of acetate and propionate on voluntary feed intake by midlactation cows. J. Dairy Sci. 81:2240-2250. 